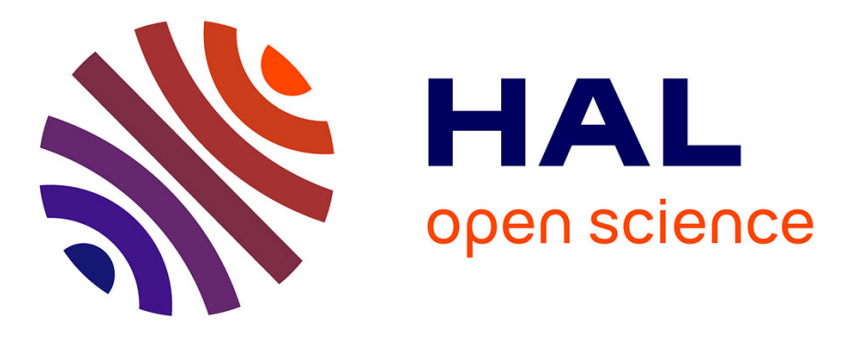

\title{
Composition, structural and optical properties of Golden grass
}

Denis G.F. David, Pascal Bargiela, Marcus Vinícius Santos da Silva, Christian Godet, Victor M. da Silva Santana, Erick Rohan Santos Oliveira Magalhães, Leonis Lourenço da Luz, Severino Alvez Junior, Jose Fernando Diniz Chubaci, Oswaldo Baffa, et al.

\section{To cite this version:}

Denis G.F. David, Pascal Bargiela, Marcus Vinícius Santos da Silva, Christian Godet, Victor M. da Silva Santana, et al.. Composition, structural and optical properties of Golden grass. Brazilian Journal of Physics, 2022, 52 (1), 10.1007/s13538-021-01000-8 . hal-03388234

\section{HAL Id: hal-03388234 \\ https://hal-univ-rennes1.archives-ouvertes.fr/hal-03388234}

Submitted on 20 Oct 2021

HAL is a multi-disciplinary open access archive for the deposit and dissemination of scientific research documents, whether they are published or not. The documents may come from teaching and research institutions in France or abroad, or from public or private research centers.
L'archive ouverte pluridisciplinaire HAL, est destinée au dépôt et à la diffusion de documents scientifiques de niveau recherche, publiés ou non, émanant des établissements d'enseignement et de recherche français ou étrangers, des laboratoires publics ou privés. 


\section{Composition, structural and optical properties of Golden}

\section{grass}

Denis Gilbert Francis David ${ }^{1}$, Pascal Bargiela ${ }^{2}$, Marcus Vinicius Santos da Silva ${ }^{1}$, Christian Godet ${ }^{3}$, Victor Mancir da S. Santana1, Erick Rohan S. O. Magalhães ${ }^{1}$, Leonis L. da Luz ${ }^{4}$, Severino Alves Júnior ${ }^{4}$, José Fernando Diniz Chubaci ${ }^{5}$, Oswaldo Baffa ${ }^{6}$, Antônio Ferreira da Silva $a^{5,1}$

1 Instituto de Física, Universidade Federal da Bahia, Campus Ondina, 40210-340 Salvador, Bahia, Brazil

2 Instituto de Química, Universidade Federal da Bahia, Campus Ondina, 40170-115, Salvador, Bahia, Brazil

3 Université de Rennes I, CNRS, Institut de Physique de Rennes - UMR 6251, 35000 Rennes, France

4 Laboratório de Terras Raras - BSTR/Universidade Federal de Pernambuco, Av. Prof. Moraes Rego, 1235 - Cidade Universitária, Recife - PE - CEP: 50670-901

5 Instituto de Física, Universidade de São Paulo, Laboratório de Cristais lônicos, Filmes Finos e Datação, 05508-090 Butantã, São Paulo, Brazil;

6 Universidade de São Paulo (USP), Faculdade de Filosofia, Ciências e Letras de Ribeirão Preto (FFCLRP) Departamento de Física (DF), Av. Bandeirantes, 3900, 14040-901 Ribeirão Preto, SP, Brasil

Corresponding author: vmsantana@ufba.br

Keywords: golden grass - characterization - optical spectroscopy - photo-electron spectroscopy

\section{Abstract}

Golden grass is a vegetal fiber used in arts and crafts for its peculiar optical properties, namely its shiny golden-like reflectivity. Since vegetal fibers structure is usually heterogeneous, complementary techniques have been used to understand the electronic properties of the external and core regions of golden grass fibers. The composition and dielectric function of the few nm-thick external surfaces has been investigated using X-ray photoelectron spectroscopy and energy loss spectroscopy (XPS-PEELS), while a comparison of vibrational and optical properties of the few-micron-thick external and fiber 
core regions was derived from Raman, optical, photoluminescence (PL) and photoacoustic (PAS) spectroscopies.

Raman signature and valence-band distribution indicate that the internal and external parts of the fibers are made of some oxygen-depleted lignin-like carbonaceous material. Besides a plasmon peak at $23.0 \mathrm{eV}$, two main absorption bands at $3.7 \mathrm{eV}$ and $9.0 \mathrm{eV}$ have been identified as $\pi-\pi^{*}$ and $\sigma-\sigma^{*}$ electronic transitions at aromatic moieties. PL excitation and emission behavior confirm heterogeneous molecular structures at the core and external regions.

Specular reflectance spectra calculated from the complex refractive index (derived from XPS-PEELS) do not explain the shiny golden-like aspect of golden grass, which may arise from diffuse reflectance within a collection of heterogeneous hollow fibers. 


\section{Introduction}

Golden Grass (Syngonanthus nitens (Bong.) Ruhland) is a native plant from the central highlands of Brazil, used to produce highly appreciated handcraft pieces due to its shiny golden-like reflectivity. Beyond the metallic appearance of golden grass vegetal fibers, its ecosystem, chemical composition and pharmacological properties have been investigated by several groups $[1,2,3]$.

Nature has several tricks to produce different colors, e.g., with the presence of chromophores which absorb or emit photons at different wavelengths, or by the way matter is arranged, giving structural or photonic color [4]. As far as golden grass is concerned, no organized photonic structures have been identified; the stems are made of ten-micron diameter fibers which rotate around the stem axis as shown by electron microscopy images reported in this work.

Inhomogeneous structural arrangements are usually found in different parts (e.g., roots, leaves or stems) of vascular plants, with a combination of carbon, oxygen and hydrogen atoms, into cellulose-like (polysaccharide) and lignin-like (phenolic) biopolymers which basically ensure rigidity and flexibility. Structural monomers of Cellulose and Lignin biopolymers correspond to a large variation of the $(\mathrm{O} / \mathrm{O}+\mathrm{C})$ ratio from 0.80 in Cellulose to about 0.35 in Lignin, as derived from XPS studies $[5,6]$. This change in global composition is reflected in the different Raman vibrational signature $[7,8,9]$ and in the valence band distribution of electronic states [10].

Investigation of the relationship between chemical composition, structural arrangements and electronic structure of vegetal carbonaceous materials is a challenge in such divided matter made of rough fibers. In particular, being all-natural materials, there is a lack of specular reflection and other desirable properties for standard optical measurements.

In this work, specific complementary techniques have been used to investigate the electronic and optical properties at different locations of golden grass fibers, including the few nm-thick external surface (X-ray photoelectron spectroscopy and photoelectron energy loss spectroscopy XPS-PEELS), and the few-micron thick external vs core regions (optical, Raman, photoluminescence and photoacoustic spectroscopies). Evidence for different molecular structure at the core and external regions of golden grass fibers is given by a detailed analysis of photoluminescence excitation and emission behavior. 
Experimental characterizations are discussed in relation with the chemical composition, Raman signature, dielectric function and valence band distribution of reference materials, namely cellulose and lignin, which are basic components of vegetal fibers. Special emphasis is given to Raman vibrational spectroscopy and valence-band distributions obtained in XPS which provide clear signatures of the golden grass structure in the external part of the fibers. The chemical composition $(\mathrm{C}, \mathrm{O}, \mathrm{Si}, \mathrm{N})$ is obtained in the topmost external surface, with a few-nm typical depth defined by the inelastic mean free path of the photoelectrons. The chemical environment of $C$ atoms is inferred from the decomposition of the $C$ 1s core level peaks in a standard analysis [5].

In addition, the energy loss distribution of photoelectrons after excitation of inter band transitions (IBTs) and plasmons along their way towards the solid surface allows the retrieval of the dielectric function (DF), using a Fourier Transform method [11]. At earlier work [12], the optical properties of zinc oxide ( $\mathrm{ZnO}$ ) nanorods (NRs) synthesized by the lowtemperature aqueous chemical method on top of silicon ( $\mathrm{Si}$ ) substrate have been also investigated by means of photoelectron energy loss spectroscopy (PEELS). Here, we perform this technique for reveal electronic properties of a sample of golden grass.

This XPS-PEELS analysis extends the characterization of electronic properties to high energies (several tens of $\mathrm{eV}$ ) that are usually not accessible by optical techniques; besides a plasmon excitation peak at $21.0 \mathrm{eV}$, two main absorption bands at $3.8 \mathrm{eV}$ and $9.0 \mathrm{eV}$ have been identified as inter band transitions in golden grass. Complementary information at low energies, derived from photoacoustic spectroscopy (PAS), confirms this absorption peak at $3.8 \mathrm{eV}$.

The complex refractive index, derived by combining photoacoustic and XPS-PEELS spectroscopies, is finally used to compute the specular reflectivity at planar surfaces for comparison with the golden-like aspect of Golden grass. 


\section{Materials and Methods}

Complementary techniques suitable for heterogeneous matter have been exploited to understand the building blocks of Golden grass and its electronic properties (dielectric function, optical and luminescence properties).

\subsection{Sample preparation and SEM images}

Golden grass samples were obtained from local craftsmen at the Brazilian city of Palmas (Tocantins), a place well known for its handcrafts production, close to the Jalapão growth region. Samples were wiped with a paper tissue and the stems were cut transversely in order to fit inside the analysis chambers. No other chemical or physical treatments were performed.

For some measurements, the stems were cut axially in order to analyze the internal part of the golden grass samples. The optical image of a fiber cross section (Fig. 1) shows some structural inhomogeneities with a porous structure and attenuated metallic reflectivity.

In electron microscopy images, a longitudinal view of the external part (Figure 1b) reveals rising tubular structures with an average diameter of 5 microns, covered by threads of tiny fibers alongside their length. A cross-section view (Figure 1a) shows the vascular tissue which transports substances throughout the plant body from one extreme end of the plant to the other, through individual hollow tubular-shaped cells. These structures, made of specialized conducting tissues, are essential to the plant metabolism: xylem channels convey water and dissolved minerals, and phloem channels conduct sugars and other organic products of photosynthesis. The xylem structures consist of waterproof lignified cell walls which also provide mechanical strength. In this way, the capillary effect in the xylem helps to pump the sap from roots to shoots and keeps the plant hydrated.

At the Fig. 2a, we can observe rising tubular structures that shape throughout the surface of the fiber. From that longitudinal view, we can observe that the tubular structures within have an average diameter of 5 microns and, in its turn, they are covered of threads of tiny fibers alongside its length, as shown in Fig. $2 b$.

In the Fig. 2c, we have a cross-section view of the fiber revealing structural inhomogeneities with a porous structure. This is because the fiber interior is composed of several elementary tubular fibers with a distribution of diameters that increases radially to the center. Each elementary tubular fiber has a thin surface skin that is adjacently merged one each other, forming a cylindrical mesh. 


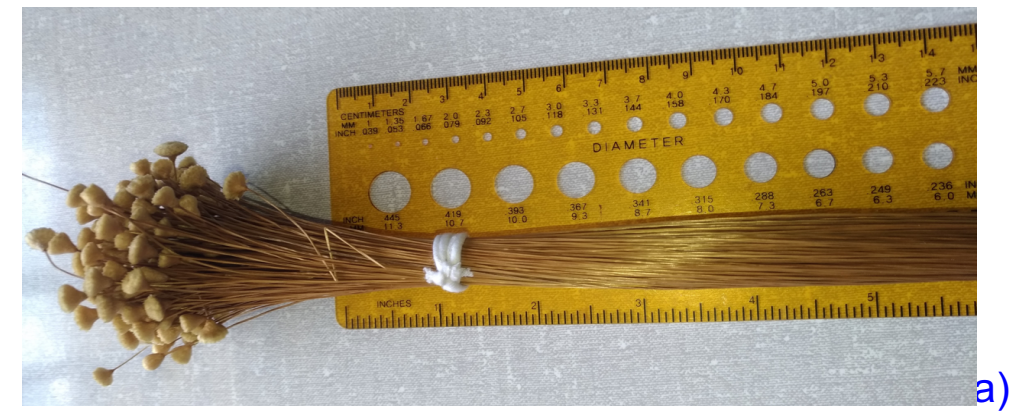

a)

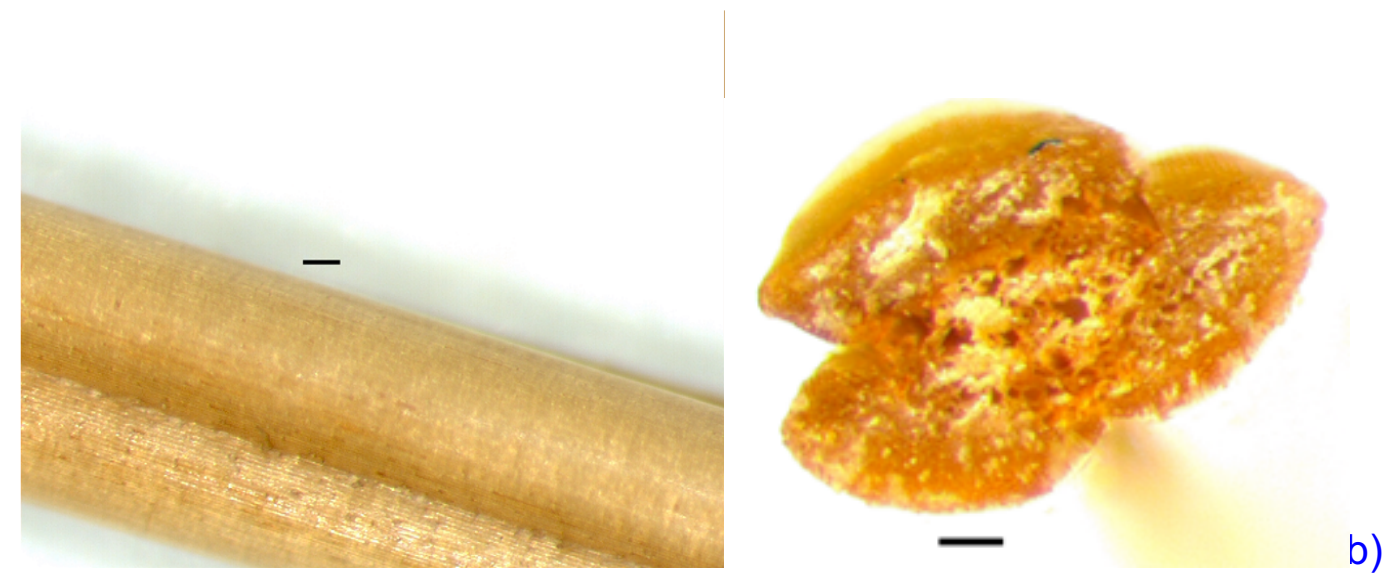

Figure 1: Golden grass sample: a) wide view of golden stalks and white flowers; b) optical microscopy images, namely external and cross section views of the same stem (horizontal bar: 100 micron scale), composed of three lobes that rotate as they progress along the axis direction.

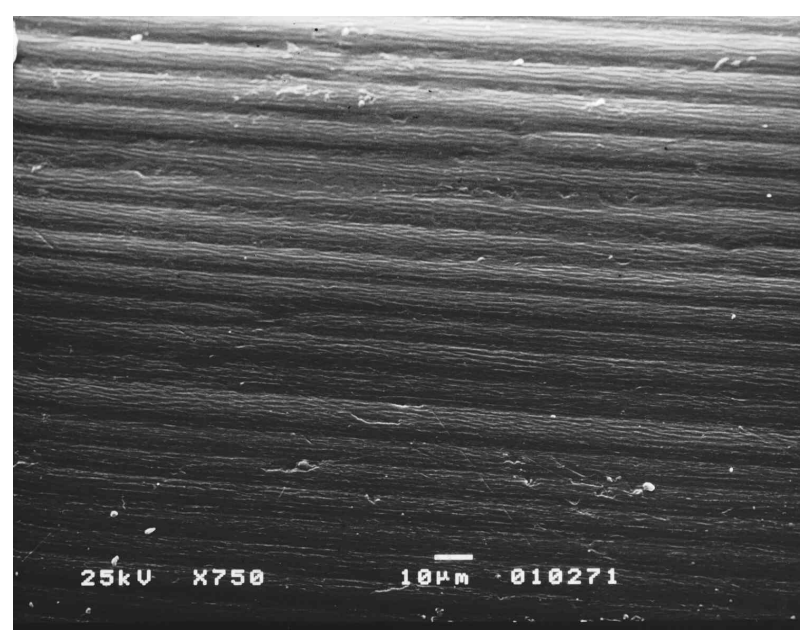



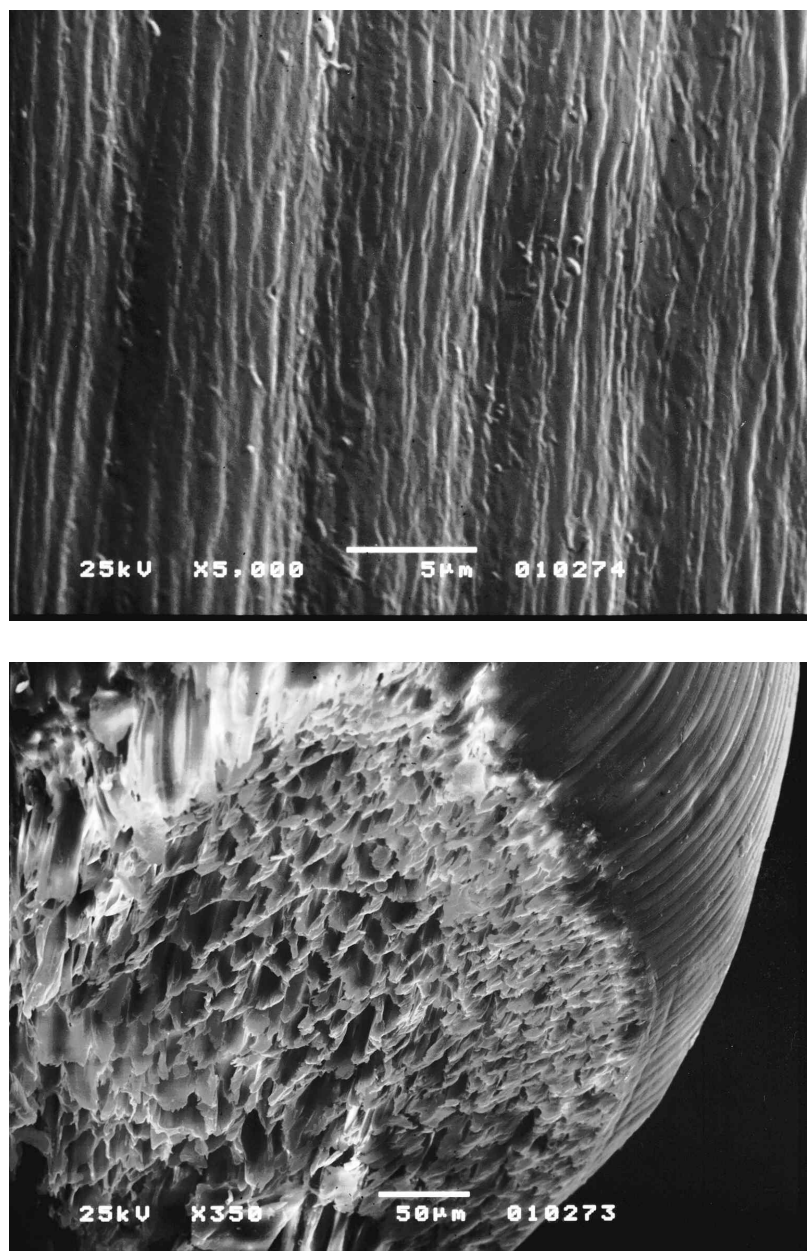

Figure 2: Scanning electron microscope images show ten-micron diameter fibers with no evidence of organized photonic structures.

\subsection{Photoacoustic spectroscopy}

Photoacoustic spectroscopy (PAS) measures the electromagnetic energy absorbed by solid matter by means of acoustic detection. The absorbed energy from a modulated photon flux causes local heating at the sample-gas interface and generates pressure (acoustic) waves in the gas. The amplitude of the pressure modulation is inversely proportional to the cell volume and modulation frequency [13]. Since the signal responds only to absorbed light, scattered light effects play no significant role in PAS measurements.

The PAS measurements were performed using a closed photoacoustic cell with ambient air, coupled to a microphone (Brüel Kjaer 2669) illuminated by a mechanically modulated $900 \mathrm{~W}$ mercury-xenon arc lamp (Newport) used as light source. The acquisition was done synchronously through a lock-in amplifier (Ithaco 3961B) with phase monitoring. Photoacoustic spectra were obtained at a modulation frequency of $20 \mathrm{~Hz}$, from the ultraviolet to mid-IR (260-2200 $\mathrm{nm}$ ) regions, and the PAS spectra were corrected for the source 
spectrum using a carbon black signal [14]. The detection limit (260 nm) is due to poor optics transparency, giving noisy spectra, above $4 \mathrm{eV}$.

The dominant contribution to the PAS signal is due to heat generated within the region between the illuminated surface and subsurface with inner distance of the thermal diffusion length $\left(\delta_{s}\right)$ defined by $\delta_{s}=\left(2 \kappa_{s} / C_{s} \rho_{s} \omega\right)^{1 / 2}$ where $\kappa_{s}, C_{s}$ and $\rho_{s}$ are the thermal conductivity, specific heat capacity, and density of the material, respectively, and $\omega$ is the modulation angular frequency. Using previously measured values of thermal diffusivity for dry leaves [15], in the range $0.12-0.58 \times 10^{-6} \mathrm{~m}^{2} \cdot \mathrm{s}^{-1}$, a thermal skin depth of $40-100$ microns can be estimated for Golden grass in this experiment.

\subsection{Raman spectroscopy}

A Raman spectrum consists of bands which are caused by inelastic scattering of photons by the chemically bonded structures. Hence Raman spectroscopy is a powerful method for the identification of chemical compounds through their vibrational properties. It is well suited for detecting molecular species in structurally complex systems such as plant tissues wherein many molecules coexist. Among the main components of vegetal fibers, the Raman signature of cellulose and lignin has been widely reported [7-9].

All measurements were carried out on a dispersive Raman spectrometer (CORA 5000s) with a Nd/YAG diode solid state laser (450 mW) centered at $1064 \mathrm{~nm}$ as excitation source. The spectra were recorded in the $100-2300 \mathrm{~cm}^{-1}$ range $\left(1.0 \mathrm{~cm}^{-1} /\right.$ pixel resolution), with spectral accumulation of 10 scans (3 seconds exposure each). The excitation energy being smaller than the optical band gap (Section 3.a), the Raman signal is thus a bulk analytical probe. The low excitation energy is also very useful to minimize the PL background.

\subsection{Photoluminescence spectroscopy}

The photoluminescence behavior of the Golden grass was recorded in a spectrofluorometer Fluorolog-3 from Horiba Jobin Yvon equipped with a 450 W Xe arc excitation lamp, doublegrating monochromator of the excitation and emission position, and R928P photomultiplier as detector. All emission spectra were corrected by spectral response of the monochromators using a silicon photodiode reference detector to monitor and compensate the variation of the xenon lamp output, using typical correction spectra provided by the manufacturer. 
Three configurations were used for PL measurements: $(A)$ a raw fiber to measure the external zone, (B) a longitudinal section to characterize the fiber core, (C) a transverse section to characterize both external and core regions. The PL emission spectra were obtained at three different excitation wavelengths: $360 \mathrm{~nm}(3.44 \mathrm{eV}), 375 \mathrm{~nm}(3.31 \mathrm{eV})$ and $480 \mathrm{~nm}(2.58 \mathrm{eV})$, with submicron depth sensitivity.

\subsection{X-ray and UV photoelectron spectroscopies}

X-ray photoelectron spectroscopy was performed in ultra-high vacuum (pressure $<10^{-6} \mathrm{~Pa}$ ) with a Kratos Axis Ultra DLD instrument using a monochromatic Al Ka X-ray source (10 mA, $12 \mathrm{kV}$ ) at $1486.6 \mathrm{eV}$. The survey spectrum of external parts of the stems was recorded with a pass energy of $80 \mathrm{eV}$, a dwell time of $100 \mathrm{~ms}$, and a resolution of $1 \mathrm{eV}$. For the main detectable elements present in the golden grass $(\mathrm{C}, \mathrm{O}, \mathrm{N}, \mathrm{Si})$, high resolution spectra were obtained with a pass energy of $40 \mathrm{eV}$, a dwell time of $200 \mathrm{~ms}$ and a resolution of $0.1 \mathrm{eV}$. A neutralizer was active during measurement for charge compensation.

In a second step, the photoelectron energy losses were recorded near the C1s core level peak, at lower kinetic energy (50 eV range). The inelastic scattering being dominated by plasmon excitations, the XPS-PEELS spectra can be analyzed using a simple dielectric model to retrieve the energy loss function (ELF) and the dielectric function (DF) of Golden grass, averaged over physically allowed wave vector values. In this procedure, the only input is the refractive index in the low energy region $[11,16]$.

Valence band spectra were obtained with X-ray excitation and with $\mathrm{He}$ II radiation (40.8 eV) in ultraviolet photoelectron spectroscopy (UPS). UPS valence band spectra of Golden grass and a silver reference were both measured to determine the Fermi level position of Golden grass. 


\section{Results}

The optical absorption of entire fibers has been measured by PAS from the infrared to the near UV. The global composition (O/C) of the fiber external envelope and the complex distribution of carbon atom environments have been obtained by XPS. Valence band and Raman spectroscopies provide valuable signatures of the structural units which compose Golden grass fibers. Photoelectron energy-loss spectra have been analyzed to derive the dielectric function over a very broad range $(0-50 \mathrm{eV})$. Finally, photoluminescence excitation and emission characteristics confirm heterogeneous molecular structures at the core and external regions of the fibers.

\subsection{Optical absorption (PAS)}

The photoacoustic spectrum (Fig. 4.a) taken on the external part of Golden grass fibers shows several spectral regions. The absorption is dominated by a strong maximum in the near-UV range, with a plateau at $3.8 \pm 0.3 \mathrm{eV}$. This peak is consistent with the absorption found in lignin compounds for aromatic ring conjugated bonds with $\mathrm{C}=\mathrm{C}\left(\pi-\pi^{*}\right.$ transitions at $320 \mathrm{~cm}^{-1}$ ) [17].

An absorption gap, in the range of $2.3 \pm 0.2 \mathrm{eV}$, has been derived from a Tauc plot, assuming a direct band gap expression (Fig. 3.b) [18, 19]. This band gap value will be used in the analysis of XPS-PEELS data.

An infrared absorption background appears at low energy below $0.9 \mathrm{eV}$ (above 1380 $\mathrm{nm})$, along with strong absorption peaks, around $1930 \mathrm{~nm}(0.64 \mathrm{eV})$ and $1500 \mathrm{~nm}(0.83$ $\mathrm{eV})$, attributed to $\mathrm{O}-\mathrm{H}$ vibrational overtones [20, 21]. The narrow peak near $1930 \mathrm{~nm}$ is related to adsorbed water (combination of the $\mathrm{H}-\mathrm{O}-\mathrm{H}$ bend and $\mathrm{O}-\mathrm{H}$ stretching modes). The wide absorption band beginning at $1380 \mathrm{~nm}$ and centered on $1500 \mathrm{~nm}$ is mainly attributed to the first $\mathrm{O}-\mathrm{H}$ stretching overtone, displaced by a variety of $\mathrm{H}$-bonding environments: water $(\sim 1440 \mathrm{~nm})$, phenolic groups of lignin $(\sim 1450 \mathrm{~nm}), \mathrm{O}-\mathrm{H}$ groups of cellulose $(\sim 1500-1580 \mathrm{~nm})$.

Weaker peaks may arise from the second C-H stretching overtone (1150-1230 nm) or some combination of aromatic $\mathrm{C}-\mathrm{H}$ stretching and bending modes (e.g. at $1417 \mathrm{~nm}$ in lignin). Besides that, the absorption at $2100 \mathrm{~nm}$ is related to a combination of $\mathrm{O}-\mathrm{H}$ or $\mathrm{C}-\mathrm{H}$ deformation and $\mathrm{O}-\mathrm{H}$ stretching vibration in cellulose and xylan. 
A broad absorption background increases continuously in the NIR range above 1400 $\mathrm{nm}$. This behavior could be related with the fact that, as the electronic states of the benzene molecules are coupled, the electrons of the $\pi$ bonds are delocalized along the aromatic ring [22]. The resulting high electronic mobility is compatible with a model of free electrons, such as the Drude model $[23,24]$.

Finally, absolute values of the absorption coefficient, $\alpha$, can be obtained by matching PAS and XPS-PEELS data (Section 3.e) at the peak energy (331 nm, $3.75 \mathrm{eV}$ ) where the complex refractive index $(n, k)=(1.95,0.81)$, i.e., $\alpha=3.1 \times 10^{5} \mathrm{~cm}^{-1}$.

Hence, the respective absorption depths, $\alpha^{-1}(E)$, amount to about 1 micron at the Raman excitation energy (1064 nm, $1.17 \mathrm{eV}$ ) and $40 \mathrm{~nm}$ at the higher PL excitation energy ( $360 \mathrm{~nm}$, $3.44 \mathrm{eV})$.

In summary, Golden grass is a wide band gap biopolymer with strong absorption in the near $\mathrm{UV}$, consistent with $\pi-\pi^{*}$ transitions in aromatic ring conjugated with $\mathrm{C}=\mathrm{C}$. 

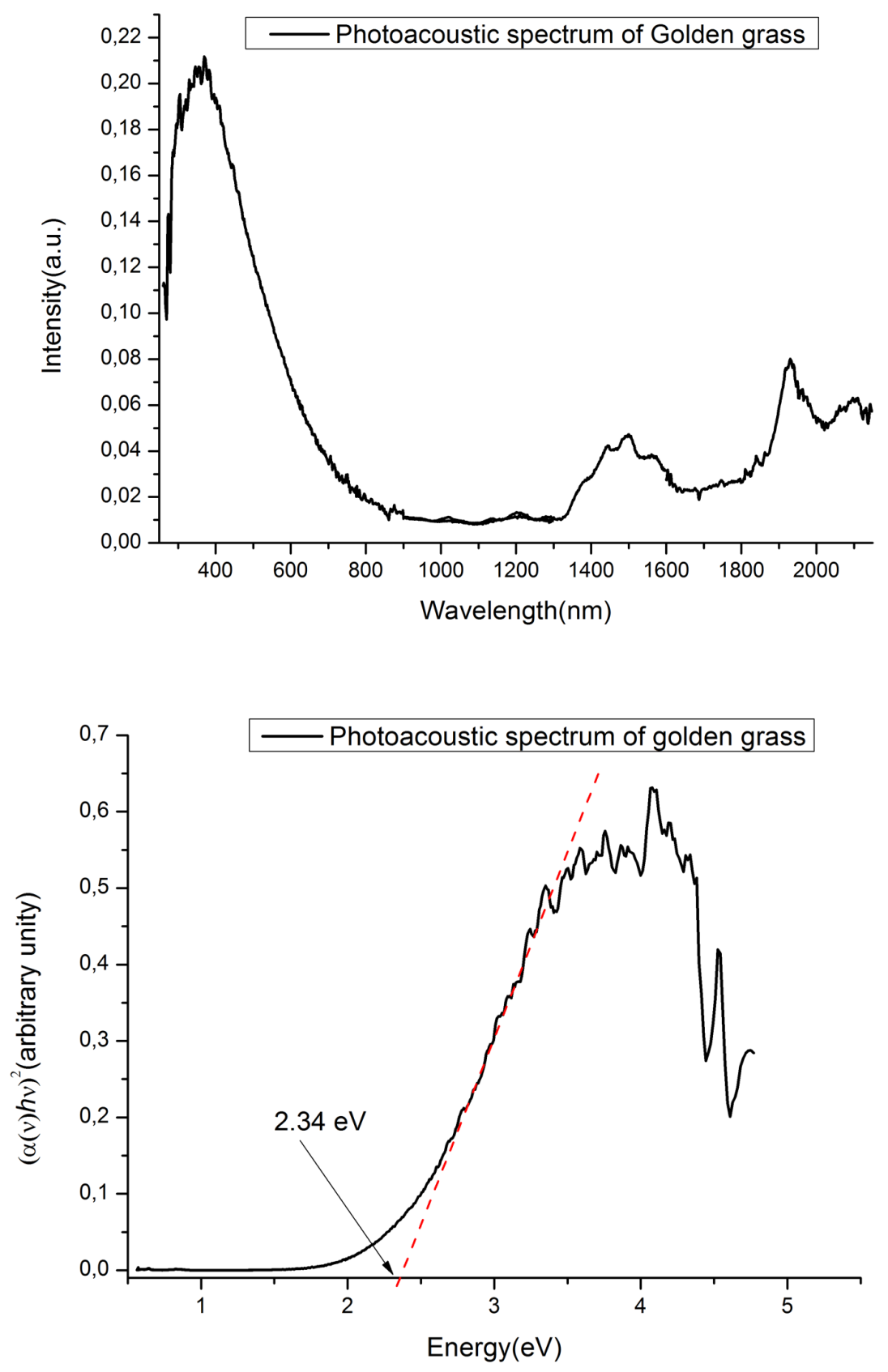

Figure 3: a) Normalized PAS absorption spectrum of Golden grass for optical wavelengths from 270 to $2100 \mathrm{~nm}$; b) Energy gap determination of golden grass, assuming a direct band gap. 


\subsection{XPS composition analysis}

The survey spectrum (Figure 4) taken on the external part of the fibers shows the predominance of carbon (main $\mathrm{C} 1 \mathrm{~s}$ line at $284.8 \mathrm{eV}$ binding energy) and oxygen (O1s line at $532.3 \mathrm{eV}$ ), along with traces of silicon (Si 2p, $102.3 \mathrm{eV}$ ) and nitrogen (N 1s, $400.1 \mathrm{eV})$.

High resolution XPS spectra reveal a complex distribution of carbon atom environments. Four core level peaks are necessary to decompose accurately the C1s line (Fig. 4.a). The additional peak at larger binding energy (near $289 \mathrm{eV}$ ) should rather be assigned to some kinetic energy loss of $\mathrm{C} 1 \mathrm{~s}$ photoelectrons due to inter band transitions, as shown by PAS (Fig. 4.b). Table 1 gives the respective strengths of $C 1 \mathrm{~s}$ peaks, attributed respectively to $\mathrm{sp}^{2} \mathrm{C}-\mathrm{C}, \mathrm{sp}^{3} \mathrm{C}-\mathrm{C}, \mathrm{C}-\mathrm{O}$ and $\mathrm{C}=\mathrm{O}$ environments. The dominant contribution $(67 \%)$ of $\mathrm{sp}^{2} \mathrm{C}-$ C environments reveals the aromatic structure of Golden grass backbone (see Discussion).

Two peaks are necessary to decompose the 01s core level peak, with respective strengths reported in Table 1. The concentration of $\mathrm{C}-\mathrm{O}$ and $\mathrm{C}=\mathrm{O}$ environments of carbon atoms is consistent with the very low $(\mathrm{O} / \mathrm{O}+\mathrm{C})$ ratio, typically 0.07 . The latter value is much smaller than that of lignin and cellulose references [5], around 0.35 and 0.80 , respectively.

In summary, the external envelope of Golden grass fibers is made of some oxygen-depleted aromatic carbonaceous material.

Table 1: Element concentrations

\begin{tabular}{|l|c|c|c|c|c|c|c|c|c|}
\hline & $\mathrm{O}(1)$ & $\mathrm{O}(2)$ & $\mathrm{C}(1)$ & $\mathrm{C}(2)$ & $\mathrm{C}(3)$ & $\mathrm{C}(4)$ & $\mathrm{Si}(1)$ & $\mathrm{Si}(2)$ & $\mathrm{N}$ \\
\hline Partial \% & 4.7 & 2.1 & 67.1 & 18.0 & 5.0 & 1.9 & 0.5 & 0.2 & 0.5 \\
\hline Total \% & \multicolumn{3}{|c|}{6.8} & \multicolumn{3}{|c|}{92.0} & \multicolumn{2}{|c|}{0.7} & 0.5 \\
\hline
\end{tabular}

Table 2: Zero-loss C1s peak parameters

\begin{tabular}{|l|l|l|l|l|}
\hline Components & Position $(\mathrm{eV})$ & Sigma $(\mathrm{eV})$ & Gamma $(\mathrm{eV})$ & Amplitude \\
\hline Peak 1 & 282.64 & .52 & 0.06 & 1835 \\
\hline Peak 2 & 283.24 & .52 & 0.06 & 470 \\
\hline Peak 3 & 284.30 & .52 & 0.28 & 44 \\
\hline Peak 4 & 285.66 & .52 & 0.30 & 13 \\
\hline
\end{tabular}




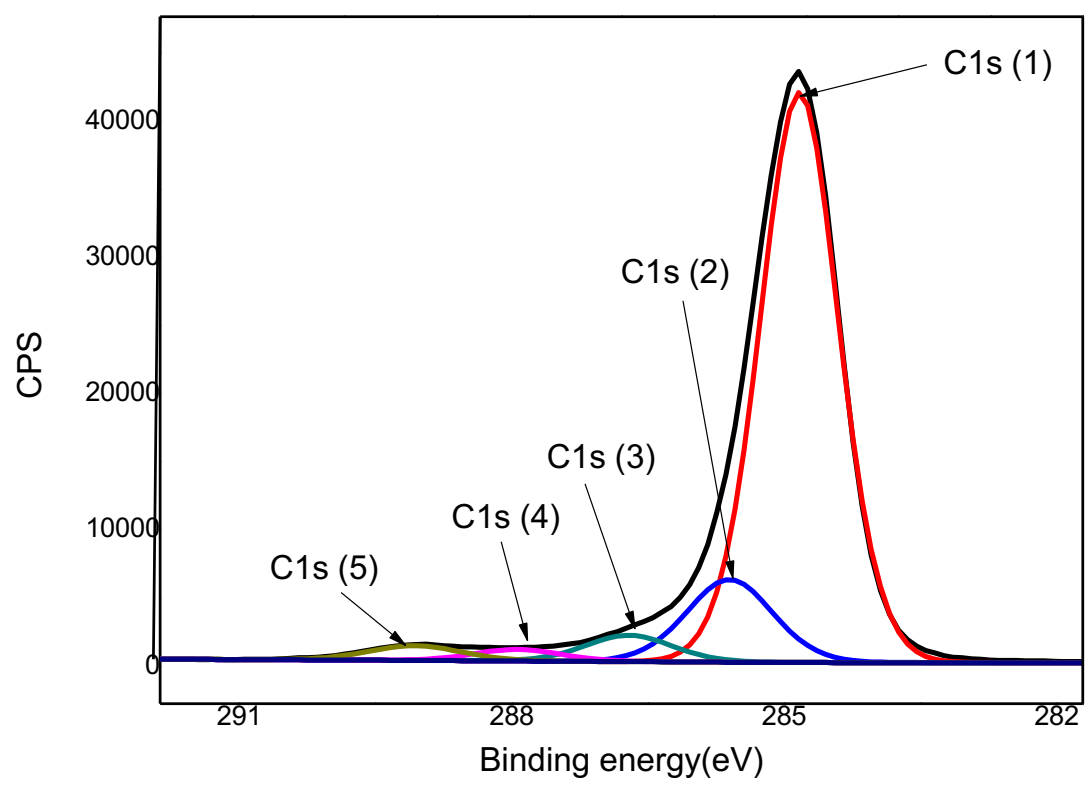

Figure 4a: High resolution XPS spectrum of the $C$ 1s region: decomposition into four core level peaks. The peak at lower kinetic energy ( $4 \mathrm{eV}$ below the main peak) is attributed to excitation of inter band transitions by $\mathrm{C} 1 \mathrm{~s}$ photoelectron.

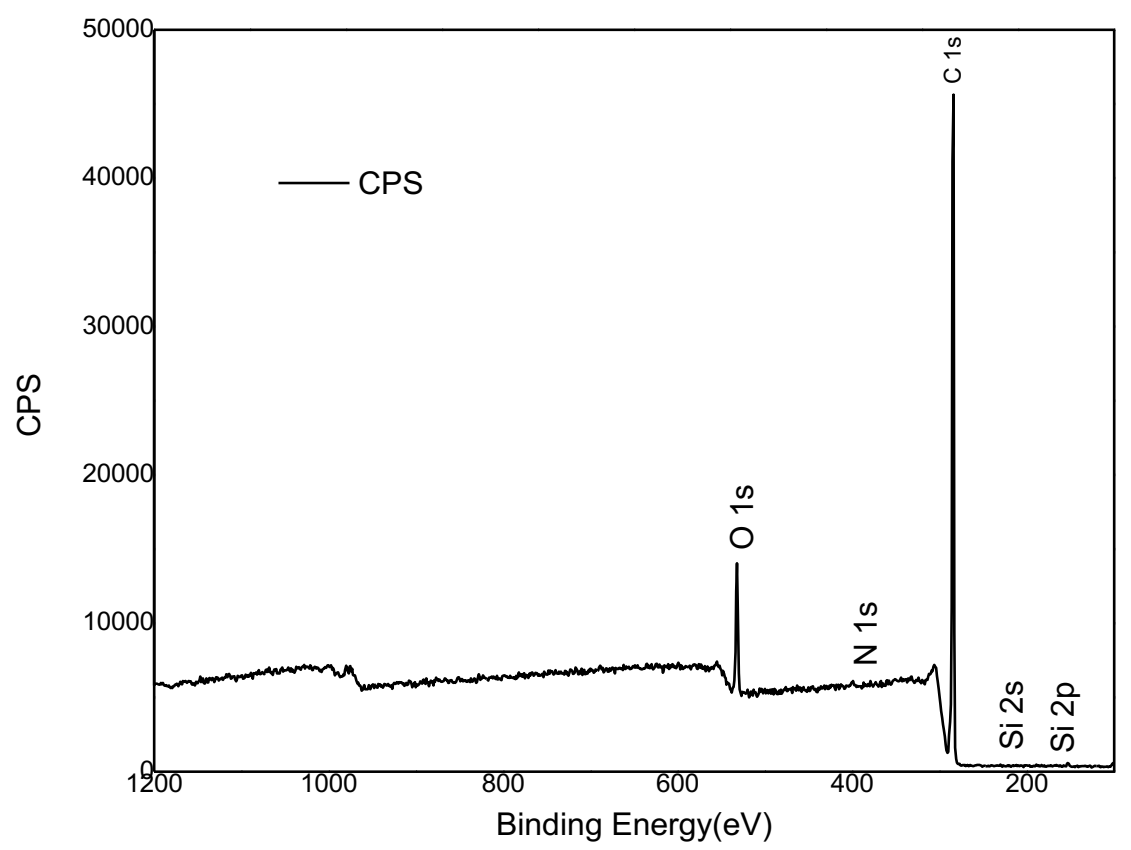

Figure 4b: The survey spectrum of the golden grass sample is dominated by carbon, with a weak presence of oxygen and some traces of silicon and nitrogen. 


\subsection{Valence band (XPS)}

The distribution of valence band electronic states was measured by XPS in order to identify the chemical structure over a few-nanometer depth at the outer surface of Golden grass fibers. The density of states between $4 \mathrm{eV}$ and $12 \mathrm{eV}$ binding energies is due to the ionization of $C 2 p$ and $O 2 p$ atomic orbitals. The deeper $C 2 s$ orbitals and $O 2 s$ orbitals are expected, respectively, near 13-22 eV and 26-30 eV binding energy. In contrast with UPS analysis, XPS is weakly sensitive to $C 2 p$ states owing to the small ionization cross-section.

The weak VB peak for $\mathrm{O} 2 \mathrm{~s}$ orbitals found near $26 \mathrm{eV}$ (Fig. 5) confirms the low oxygen content of the near surface region. Hence, the valence band spectrum at the surface of Golden grass is very different from the valence band spectrum of cellulose which is dominated by the $\mathrm{O} 2$ s peak $[25,26]$.

The overall aspect of the VB of golden grass has strong similarity with that of polyethylene [27], however this is inconsistent with the large $\mathrm{sp}^{2} \mathrm{C}$ component found by XPS. It should rather be compared with Lignin and its structural monomers [10]: cinnamyl alcohol and coniferyl alcohol. The well-defined double peak signature at 13.4 and $19.3 \mathrm{eV}$ observed in Golden grass is absent in Lignin, in contrast with Lignin monomers, particularly cynnamyl alcohol. However, the narrow peak at $13.6 \mathrm{eV}$ binding energy, due to the ionization of $\mathrm{C} 2 \mathrm{~s}$ molecular orbitals, is strongly enhanced in Golden grass.

In summary, the electronic structure of the external envelope of Golden grass fibers is close to that of a building block of Lignin (cynnamyl alcohol) with some enhancement of the narrow peak at $13.5 \mathrm{eV}$ binding energy.

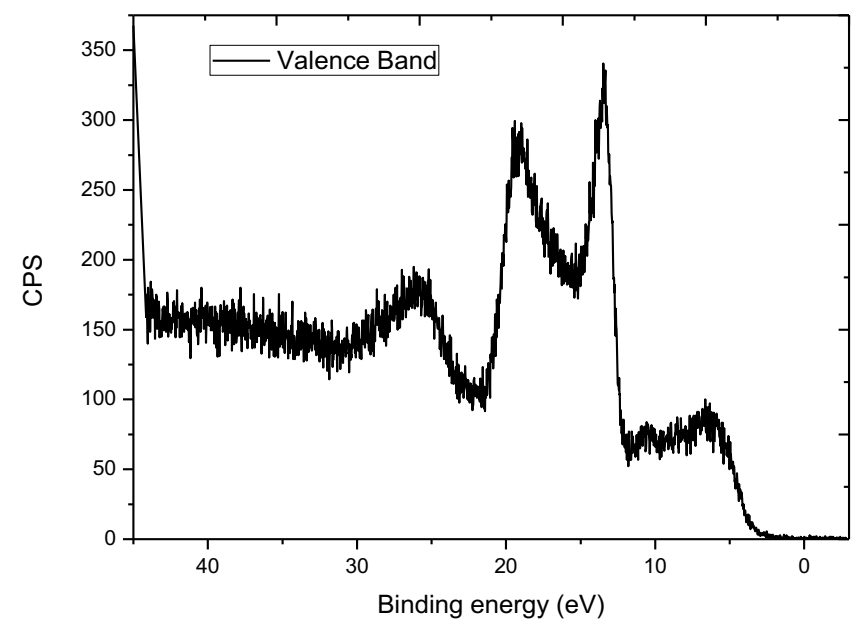

Figure 5: Valence Band of Golden grass measured by XPS 


\subsection{Raman vibrational signature}

Cellulose and lignin provide the most prominent Raman bands in wood and grass, with specific vibrational signatures. In Golden grass, all the observed peaks between $380 \mathrm{~cm}^{-1}$ and $1500 \mathrm{~cm}^{-1}$ are attributed to cellulose (cellulose, hemicelluloses, etc.), while the stronger peaks around $1600 \mathrm{~cm}^{-1}\left(1603,1620,1660 \mathrm{~cm}^{-1}\right)$ are attributed to lignin [8]. The hemicellulose signature near $1000 \mathrm{~cm}^{-1}$ [9] remains below the detection level.

The dominant multicomponent peak observed near $1600 \mathrm{~cm}^{-1}$ (Fig. 6) is similar to that reported in the Lignin reference spectrum while this peak is absent in the Cellulose reference [9]. The strong peaks at 1603 and $1625 \mathrm{~cm}^{-1}$ are attributed to CC stretching modes, respectively in aromatic and $\mathrm{C}=\mathrm{C}$ bonding units, while the weak peak at $1660 \mathrm{~cm}^{-1}$ results from the carbonyl group $\mathrm{C}=\mathrm{O}$ in conjugated ketones (aryl and diaryl ketones) or aldehydes $\mathrm{C}=\mathrm{C}-\mathrm{C}=\mathrm{O}[27,28]$.

An interesting Raman signature is that of aldehyde moieties with characteristic band at 1121 $\mathrm{cm}^{-1}$, very close to the $1132 \mathrm{~cm}^{-1}$ band present in coniferyl aldehyde and absent in vanillylidenacetone [29]. The characteristic Raman signal at $1092 \mathrm{~cm}^{-1}$, is attributed to $\mathrm{CH}$ and $\mathrm{CH} 2$ stretching and asymmetric stretching vibration of the C-O-C glycosidic linkage [7].

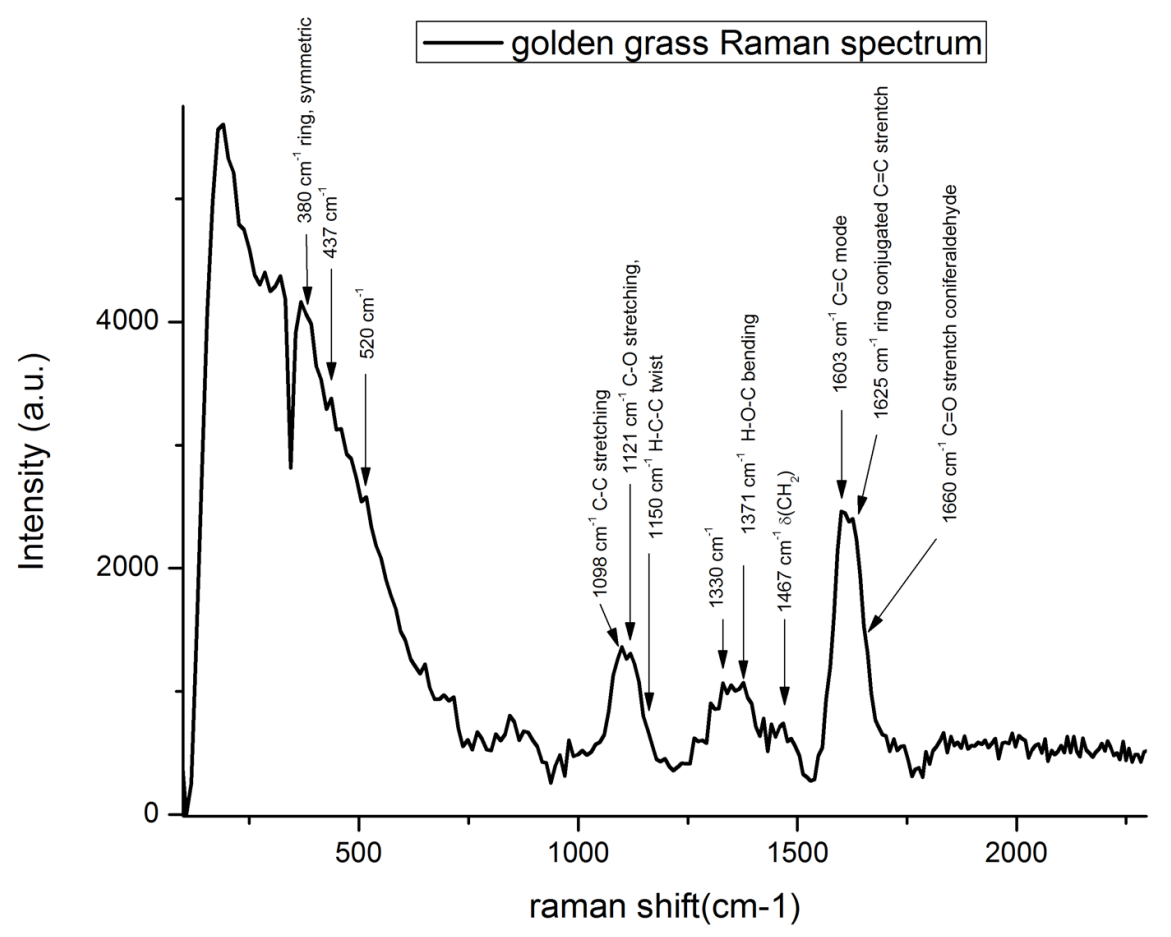

Figure 6: Raman spectra assignments of Golden grass. 
At low energies, a strong background (extending below $700 \mathrm{~cm}^{-1}$ ) is due to Rayleigh scattering arising from density fluctuations; the peaks or shoulders observed at $380 \mathrm{~cm}^{-1}$, $437 \mathrm{~cm}^{-1}$ and $520 \mathrm{~cm}^{-1}$ are attributed to symmetric bending $\delta(\mathrm{CCC})$ and stretching, ring $\mathrm{v}(\mathrm{CCO})$ and glycoside $\mathrm{v}(\mathrm{COC})$.

\subsection{Photoelectron energy loss spectroscopy (XPS-PEELS)}

In this work, a Fourier transform method was used to derive the dielectric function from the photoelectron energy-loss spectrum associated to one of its photoemission lines, as described in reference [12]. This algorithm removes the core-level shape, eliminates the experimental broadening factors and separates the various inelastic scattering orders. In a simple dielectric model, the resulting energy loss function (ELF) due to plasmon excitation and inter band transitions, is used to derive the dielectric function of a solid from its photoelectron energy-loss spectrum.

In the case of Golden grass, the zero-loss peak given by a sum of four Lorentzian C1s peaks $(\delta=0.04 \mathrm{eV}$ ) (Table 2 ) is convoluted by the X-ray source Lorentzian profile (monochromatic, $\Gamma=0.03 \mathrm{eV}$ ) and by the spectrometer Gaussian function ( $\sigma=0.57 \mathrm{eV}$ ) which dominates the experimental band width. In contrast with metals where the line shape is affected by the creation of electron-hole pairs near the Fermi energy, no additional asymmetry is required since Golden grass is a wide band gap material $\left(E_{G}=2.8 \mathrm{eV}\right)$.

As shown in Fig. 8, the ZLP subtraction is rather good. At low loss energies, the main ELF feature is a peak at $4.2 \mathrm{eV}$. This energy loss mechanism is attributed to some $\pi-\pi^{*}$ inter band transition. In spite of their different depth sensitivities, the agreement between PAS and XPS-PEELS in the visible region is quite good. The broader peak width in PAS analysis is consistent with its depth integration over several tenths of microns whereas XPS-PEELS probes the fem-nm tick external envelope of the fibers.

The dielectric function (Fig. 9) shows a clear separation of $\pi-\pi^{*}$ inter band transitions (3.7 $\mathrm{eV})$ and $\sigma-\sigma^{*}$ inter band transitions (8.2 eV).

Specular reflectance spectra calculated from the complex refractive index (derived from XPS-PEELS) show some maximum in the blue and minimum in the red part of the spectrum. The calculated values remain rather small and do not show any resonance in the yellow range; overall, these results do not explain the shiny golden-like aspect of Golden grass. 


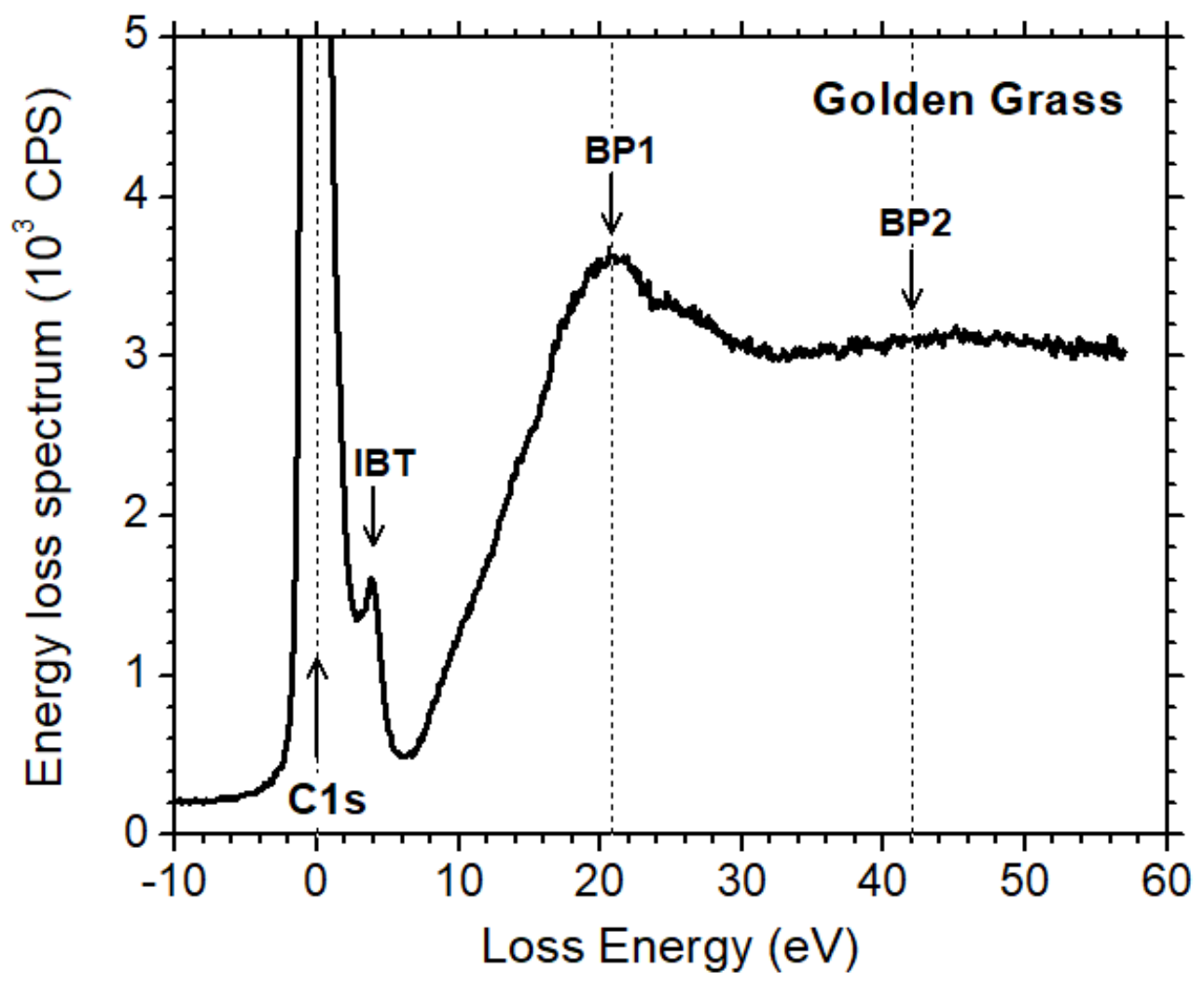

Figure 7: Energy-loss spectrum associated to the $\mathrm{C} 1 \mathrm{~s}$ core level.

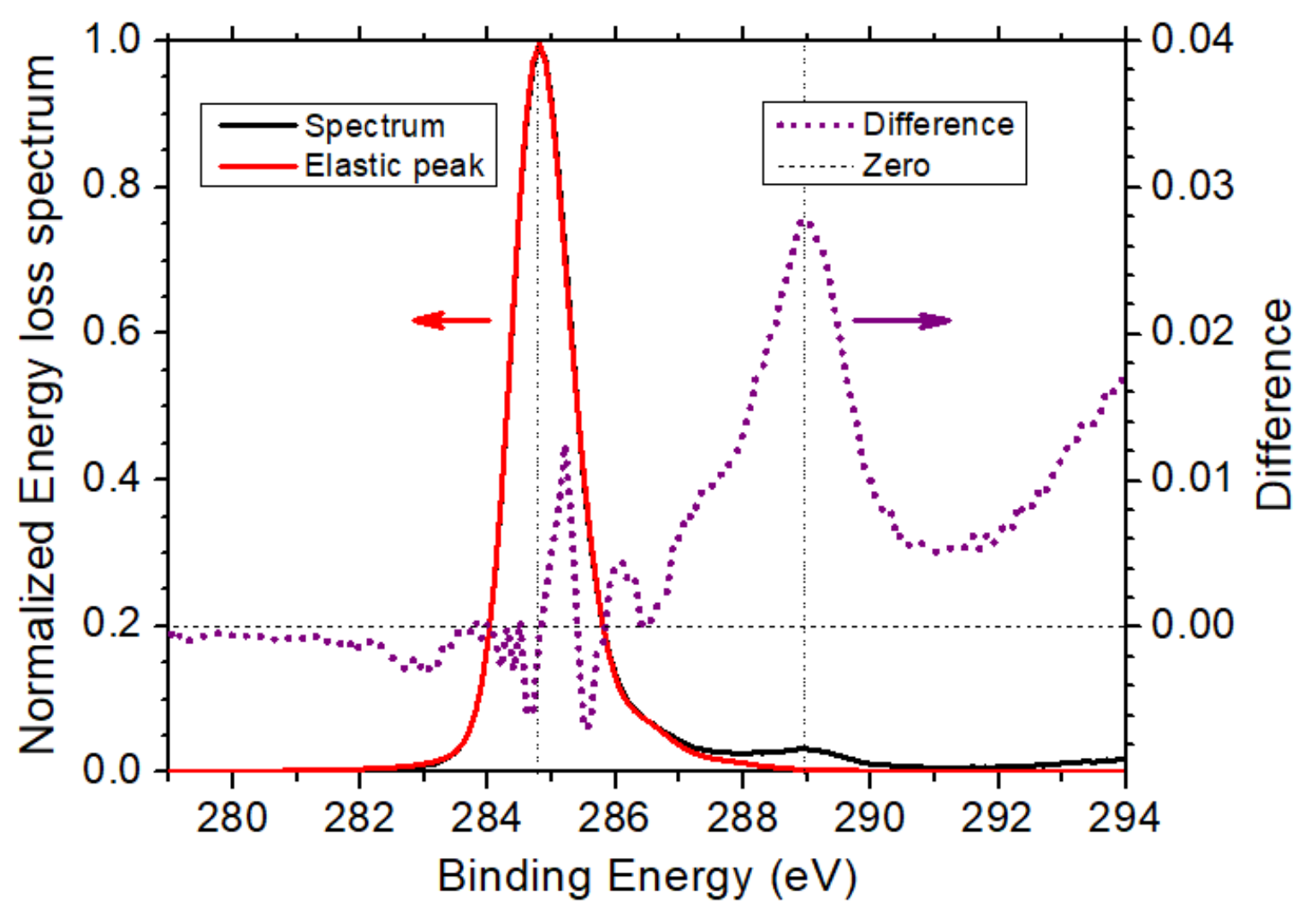

Figure 8: Modeled ZLP due to the composite $\mathrm{C} 1 \mathrm{~s}$ line (red), experimental spectrum (black) and difference spectrum (violet) giving the energy-loss distribution for $C$ 1s photoelectrons. 


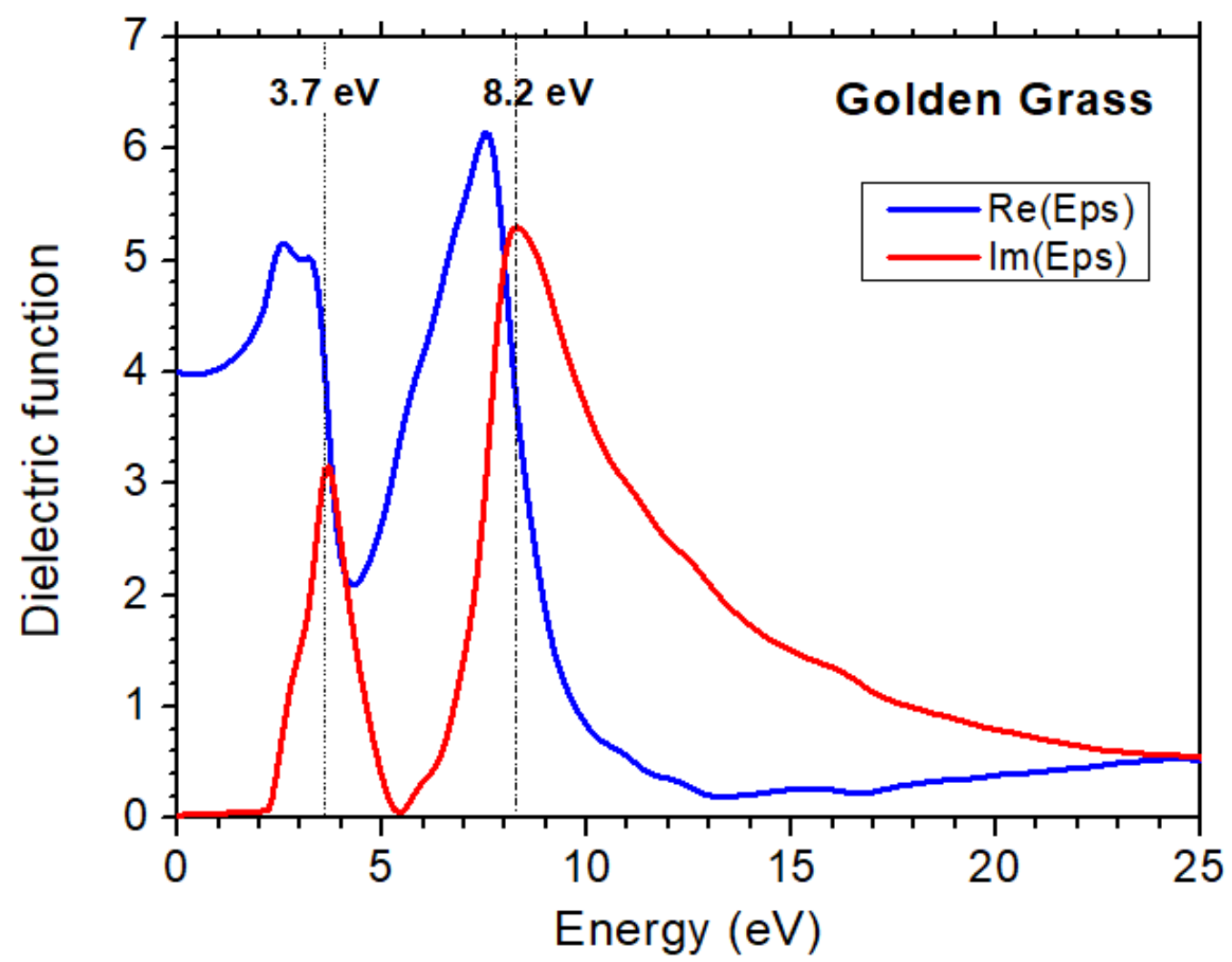

Figure 9: Dielectric function of near-surface region derived from XPS-PEELS.

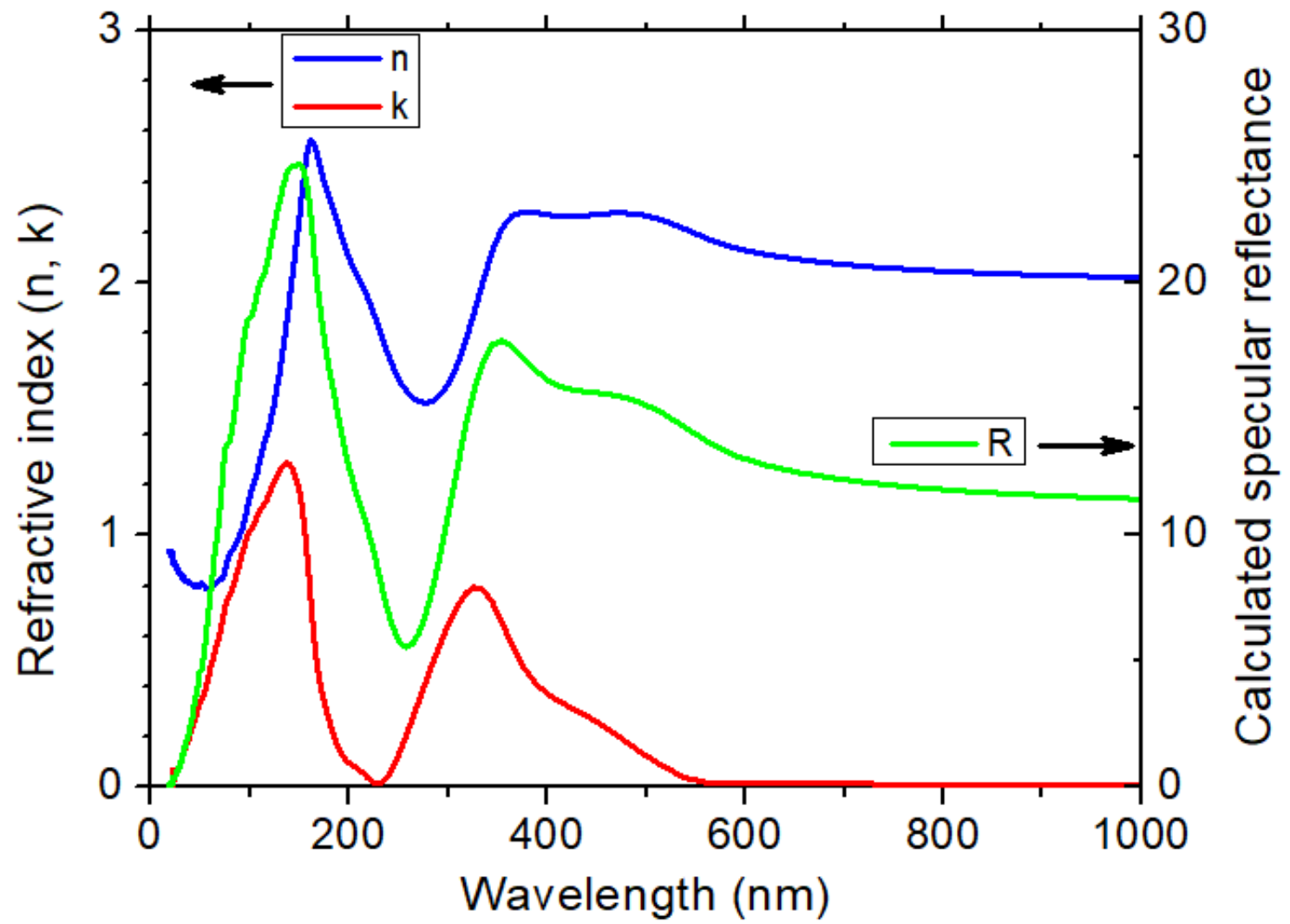

Figure 10: Complex refractive index $(\mathrm{n}, \mathrm{k})$ and specular reflectivity $R$ versus wavelength. The arrows indicate the corresponding the axis for each optical quantity. 


\subsection{Photoluminescence analysis}

PL emission spectra were obtained at three excitation wavelengths, $360 \mathrm{~nm}, 375 \mathrm{~nm}$ and $480 \mathrm{~nm}$, in three exposure configurations (Fig. 11e): (A) external region (entire fiber), (B) fiber core (longitudinal section), $(C)$ both external and core regions (transverse section). The main difference between the external region (entire fiber) and the core region (longitudinal section) of the fibers is obtained for the excitation at $375(3.31 \mathrm{eV})$ and $360 \mathrm{~nm}(3.44 \mathrm{eV})$, respectively.

The fiber core (longitudinal section) displays distinct emission bands with maximum at 445 $\mathrm{nm}(2.79 \mathrm{eV})$ and $560 \mathrm{~nm}(2.21 \mathrm{eV})$ under excitation at $360 \mathrm{~nm}(3.44 \mathrm{eV})$ and $480 \mathrm{~nm}(2.58$ $\mathrm{eV}$ ), respectively (Fig. 11b). In contrast, the external region (entire fiber) excited in the UV $\left(\lambda_{\mathrm{Ex}}=375 \mathrm{~nm}\right)$ shows a very wideband emission covering the entire visible electromagnetic spectrum (Fig. 11a). However, the PL of the entire fiber under blue excitation $\left(\lambda_{\mathrm{Ex}}=480 \mathrm{~nm}\right)$ exhibits a spectral profile similar to that of the longitudinal section.

In the following, the emission peaks in Fig. 11 are referenced in a chromaticity diagram [30]. As a result, the external region (entire fiber) fiber shows reddish and pale-yellow photoluminescence color with CIE chromaticity coordinates $(x, y)$ of $(0.531,0.451)$ and $(0.368,0.377)$, respectively, while the fiber core (longitudinal section), exhibits reddish and blue photoluminescence color with CIE chromaticity coordinates $(x, y)$ of $(0.521,0.460)$ and $(0.183,0.229)$, respectively (Fig. 11c-d). The dominant wavelength and color purity as compared to the 1931 CIE Standard Source $[\mathrm{C}=(0.3101,0.3162)]$ were $577 \mathrm{~nm}$ and $10.4 \%$ $\left(\lambda_{\mathrm{Ex}}=375 \mathrm{~nm}\right)$ and 584.5 and $92.9 \%\left(\lambda_{\mathrm{Ex}}=480 \mathrm{~nm}\right)$, for the external region, and $482 \mathrm{~nm}$ and $30 \%\left(\lambda_{\mathrm{Ex}}=360 \mathrm{~nm}\right)$ and 583 and $90.1 \%\left(\lambda_{\mathrm{Ex}}=480 \mathrm{~nm}\right)$, for the core of Golden grass fibers.

In summary, we have verified that PL emission color of golden grass can be tuned by the excitation source. The different PL excitation and emission behavior outside and inside the Golden grass fiber give evidence of different molecular structures. In addition, the internal part of the longitudinal section produces more intense PL emission that the external envelope, since the wide PL emission band of the entire fiber is composed by cofluorescence of internal and external parts. 
a)

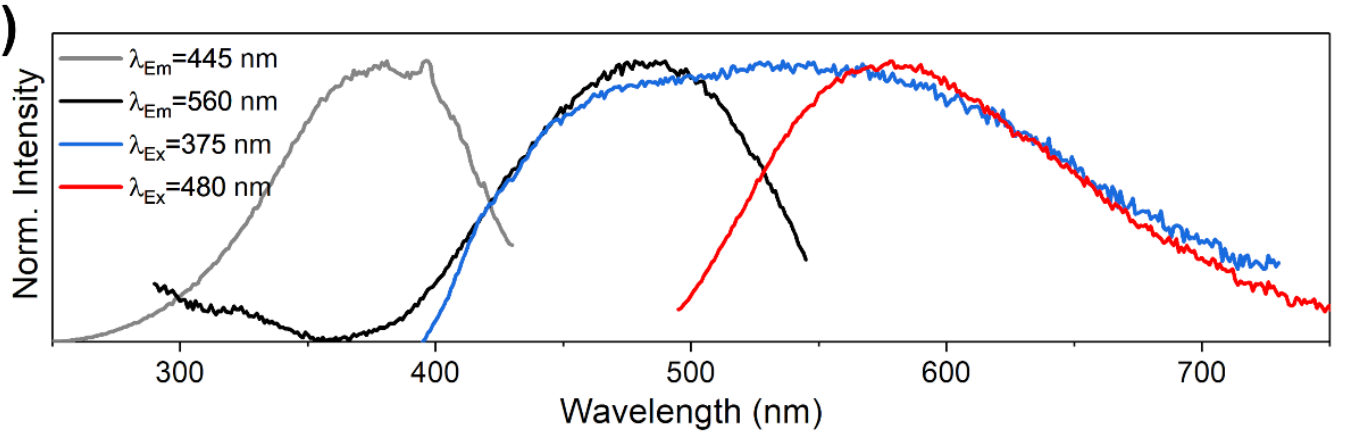

b)

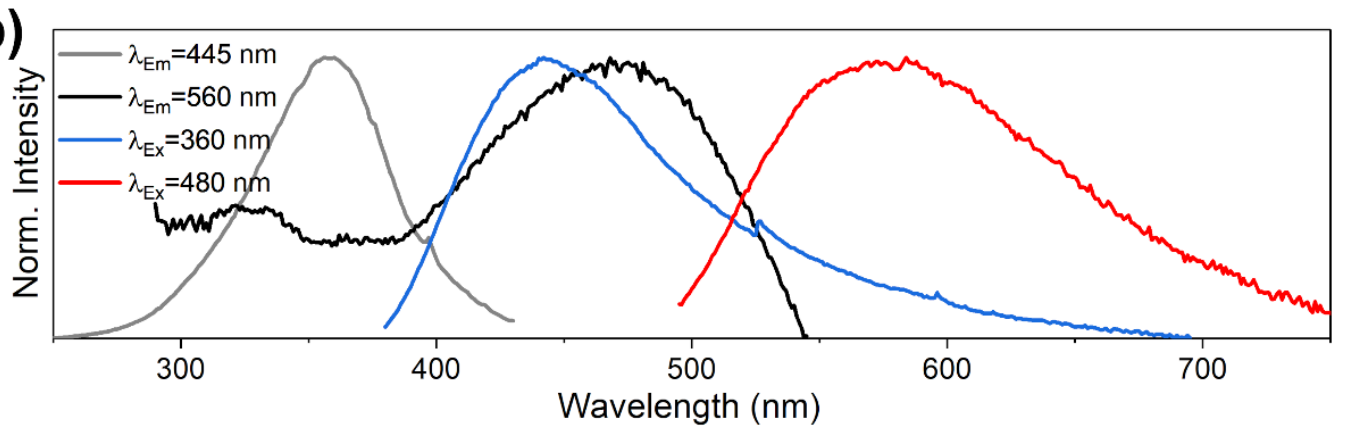

c)
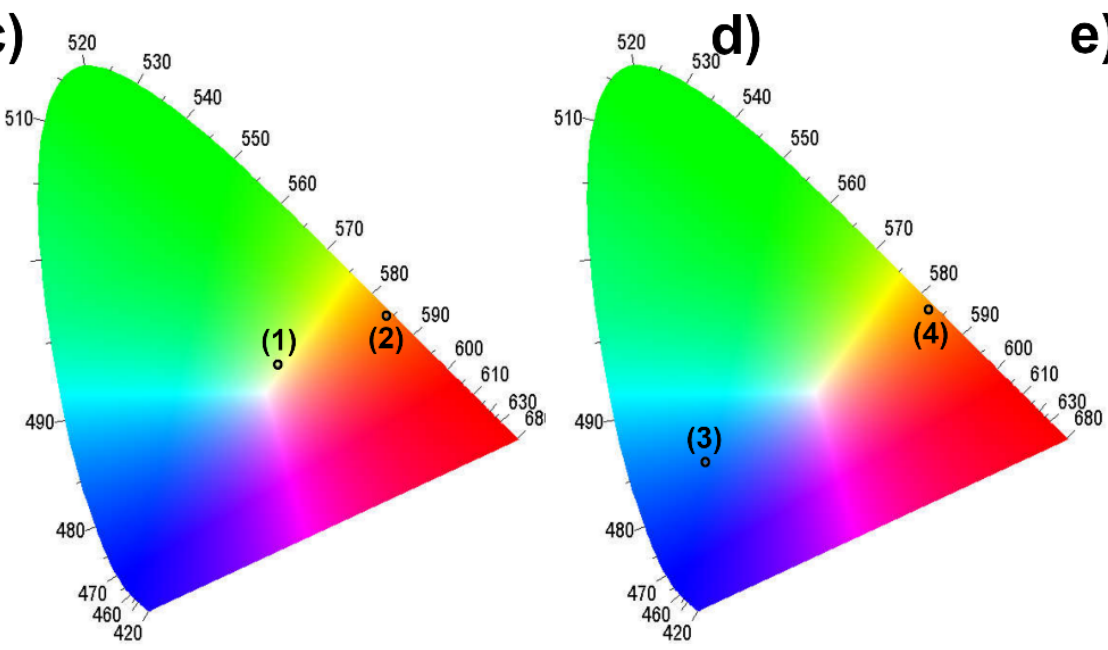

e)

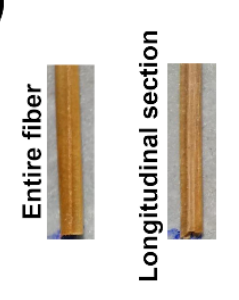

Figure 11: Emission (blue and red lines) and excitation (gray and black lines) spectra of the external part (entire fiber) (a) and core region (longitudinal section) (b) of Golden grass fiber. CIE chromaticity diagram [30] of the external part (entire fiber) (c) and core region (longitudinal section) (d) of Golden grass fiber. e) Picture of entire fiber and longitudinal section of Golden grass fiber. 


\section{Discussion}

The electronic properties of Golden grass derived from XPS-PEELS, photoluminescence and PAS spectroscopies can be tentatively related to composition and structural information given by XPS, Raman vibrational properties and valence band signature.

\subsection{Electronic properties}

In this study, we have found that Golden grass is a wide band gap biopolymer $\left(E_{\mathrm{G}}=2.3 \pm 0.2\right.$ $\mathrm{eV}$ ) with strong absorption in the near UV, consistent with $\pi-\pi^{*}$ transitions in aromatic rings conjugated with $\mathrm{C}=\mathrm{C}$. Weak IR absorption bands at $0.65 \mathrm{eV}$ and $0.83 \mathrm{eV}$ are attributed to $\mathrm{OH}$ vibration overtones, respectively in adsorbed water and phenolic compounds.

The dielectric function derived from XPS-PEELS shows a clear separation of $\pi-\pi^{*}(3.7 \mathrm{eV})$ and $\sigma-\sigma^{*}(8.2 \mathrm{eV})$ inter band transitions. In spite of their different depth sensitivities, the agreement between PAS and XPS-PEELS in the visible region is rather good.

This study also reveals that Golden grass is a good absorber of ultraviolet light, for both UVA photons at 315-400 nm (3.1-3.94 eV) and UVB photons at 280-315 nm (3.94-4.43 eV).

The fiber core (longitudinal section) displays distinct emission bands with maximum at 445 $\mathrm{nm}(2.79 \mathrm{eV})$ and $560 \mathrm{~nm}(2.21 \mathrm{eV})$ under excitation at $360 \mathrm{~nm}(3.44 \mathrm{eV})$ and $480 \mathrm{~nm}(2.58$ $\mathrm{eV}$ ), respectively. In contrast, the external region (entire fiber) excited in the UV ( $\lambda_{\mathrm{Ex}}=375$ $\mathrm{nm}$ ) shows a very wideband emission covering the entire visible electromagnetic spectrum (Fig. 11a). However, the PL of the entire fiber under blue excitation $\left(\lambda_{\mathrm{Ex}}=480 \mathrm{~nm}\right)$ exhibits a spectral profile similar to that of the longitudinal section.

\subsection{Composition and structural units}

XPS reveals that the external envelope of the fibers is made of some oxygen-depleted carbonaceous material $(\mathrm{O} / \mathrm{O}+\mathrm{C}=0.07)$ with dominant $\mathrm{sp}^{2} \mathrm{C}-\mathrm{C}$ environments $(67 \%)$. In Raman spectra, the dominant multicomponent peak observed near $1600 \mathrm{~cm}^{-1}$ is similar to the Lignin reference spectrum while this peak is absent in Cellulose. A large amount of aromatic and $\mathrm{C}=\mathrm{C}$ bonding units is observed, along with carbonyl groups $\mathrm{C}=\mathrm{O}$ in conjugated ketones (aryl and diaryl ketones) or aldehydes $\mathrm{C}=\mathrm{C}-\mathrm{C}=\mathrm{O}$.

Hence, the carbon binding is probably a mixture of olefinic and aromatic moieties as found in some precursors of Lignin: a) the valence band electronic structure is similar to that found in cinnamyl alcohol $\left(\mathrm{C}_{9} \mathrm{H}_{10} \mathrm{O}\right)$; b) characteristic Raman bands of some aldehyde groups are 
consistent with coniferyl aldehyde $\left(\mathrm{C}_{10} \mathrm{H}_{10} \mathrm{O}_{3}\right)$ where the carbonyl group $\mathrm{C}=\mathrm{O}$ is conjugated to the aryl moiety. These molecules form a family of rigid and nearly planar structural units due to $\pi$-bond conjugation. They have been identified as Lignin structural monomers.

It may seem surprising that structural monomers can be detected in Golden grass. The depolymerization of the Lignin component cannot be excluded under exposure to X-rays in XPS experiments, which could produce photoionization at some particular sites; electron removal is an oxidative process which might trigger the production of aromatic aldehydes [31]. Further studies should confirm whether this is an intrinsic property of Golden grass or the result of some chemical evolution under X-ray exposure.

DFT studies may also be useful to confirm the origin of the well-defined double peak signature at 13.5 and $19 \mathrm{eV}$ observed in the VB of Golden grass and discriminate between different Lignin monomers.

\subsection{Dielectric function and reflectance properties}

Specular reflectance spectra have been calculated from the complex refractive index (derived from XPS-PEELS), giving a small reflection coefficient, weak spectral modulation and no enhancement of the golden color (580 nm) (Fig. 10). Hence, the Fresnel coefficients calculated for an ideally abrupt planar interface between linear, homogeneous and isotropic media, are not sufficient to explain the shiny golden-like aspect of golden grass fibers.

However, some evidence of Golden grass inhomogeneity and porosity has been gathered from electron microscopy images (Fig. 2) and from PL excitation and emission spectroscopies (Fig. 11). A more appropriate optical model should rather consider diffuse reflectivity of weakly absorbed photons within a collection of heterogeneous fibers.

Let us consider a very general structural model of wood or paper described by hollow fibers [32]. In an optical model where the external fiber and hollow core diameters are much larger than the incident light wavelength, the partial reflectance calculated for many orders of multiple reflection or refraction shows that, in the transparency region, the diffuse reflectance is increased by a large factor for odd reflection / refraction orders.

In the context of diffuse reflection by heterogeneous solids, the energy dependence of the complex refractive index must also be considered. As shown in [32], weakly absorbed photons experience multiple reflection and refraction events at any of the internal interfaces. 
In contrast, at strongly absorbed wavelengths, specular reflection will dominate since multiple scattering is strongly suppressed.

In Golden grass, a strong enhancement of diffuse reflection is thus expected in the quasitransparency region (red and yellow photons) in contrast with the strongly absorbing region (blue and green photons).

\section{Conclusions}

Complementary spectroscopic characterizations of Golden grass (Syngonanthus nitens) fibers were performed with different in-depth sensitivities. Golden grass is a wide band gap biopolymer with good absorption of both UBA and UVB ultraviolet photons. Its shiny golden aspect is attributed to diffuse reflection of weakly absorbed photons within a collection of heterogeneous fibers.

Raman signature and valence-band distribution indicate that the internal and external parts of the fibers are made of some oxygen-depleted lignin-like carbonaceous material, close to the coniferyl aldehyde precursor of Lignin. Besides a plasmon excitation peak at $21 \mathrm{eV}$, two main absorption bands at $3.8 \mathrm{eV}$ and $9 \mathrm{eV}$ have been identified as $\pi-\pi^{*}$ and $\sigma-\sigma^{*}$ electronic transitions at aromatic moieties. Photoluminescence excitation and emission behavior confirm heterogeneous molecular structures at the core and external regions.

In summary, a strong enhancement of diffuse reflection of red and yellow photons seems to be responsible for the yellowish metallic aspect of the color.

\section{Acknowledgments}

The authors acknowledge financial support from the Brazilian agencies: CNPq (Project No. 303304/2010-3, 304107/2019-0), USP (Proc. 2019.1.971.43.0), FAPESB (Nos. PNX 0007/2011 and INT0003/2015) and CAPES, finance code 001. 


\section{References}

[1] Pacifico, M., Napolitano, A., Masullo, M., Hilario, F., Vilegas, W., Piacente, S., dos Santos, L. C. (2011). Metabolite fingerprint of "capim dourado" (Syngonanthus nitens), a basis of Brazilian handcrafts. Industrial crops and products, 33(2), 488-496.

[2] Berlim, L. S., Gonçalves, H. A., de Oliveira, V. S., Mattoso, N., Prudente, A. S., Bezerra Jr, A. G., Schreiner, W. H. (2014). Syngonanthus nitens: Why it looks like spun gold. Industrial Crops and Products, 52, 597-602.

[3] Berlim, L. S., Bezerra Jr, A. G., Pazin, W. M., Ramin, T. S., Schreiner, W. H., Ito, A. S. (2018). Photophysical properties of flavonoids extracted from Syngonanthus nitens, the golden grass. Journal of Luminescence, 194, 394-400.

[4] Burg, S. L., Parnell, A. J. (2018). Self-assembling structural colour in nature. J. Phys.: Condens. Matter, 30, 413001.

[5] Johansson, L. S., Campbell, J. M., Koljonen, K., Stenius, P. (1999). Evaluation of surface lignin on cellulose fibers with XPS. Applied surface science, 144, 92-95

DOI: 10.1016/S0169-4332(98)00920-9

[6] Salaneck, W. R. (1984). Photoelectron spectroscopy of the valence electronic structure of polymers. Crit. Rev. Sol. State, 12, 267-296.

[7] Alves, A. P. P., de Oliveira, L. P., Castro, A. A., Neumann, R., de Oliveira, L. F., Edwards, H. G., Sant'Ana, A. C. (2016). The structure of different cellulosic fibres characterized by Raman spectroscopy. Vibrational Spectroscopy, 86, 324-330.

[8] Agarwal, U. P. (2019). Analysis of cellulose and lignocellulose materials by Raman spectroscopy: A review of the current status. Molecules, 24(9), 1659.DOI: 10.3390/molecules24091659

[9] Kouadri, I., Satha, H. (2018). Extraction and characterization of cellulose and cellulose nanofibers from Citrullus colocynthis seeds. Industrial crops and products, 124, 787-796.

DOI: 10.1016/j.indcrop.2018.08.051

[10] Klarhoefer, L., Roos, B., Vioel, W., Hoefft, O., Dieckhoff, S., Kempter, V., MausFriedrichs, W. (2008). Valence band spectroscopy on lignin. Holzforschung, 62(6), 688693. DOI 10.1515/HF.2008.116c

[11] da Silva Santana, V. M., David, D., de Almeida, J. S., Godet, C. (2018). Photoelectron energy loss in $\mathrm{Al}(002)$ revisited: retrieval of the single plasmon loss energy distribution by a Fourier transform method. Brazilian Journal of Physics, 48(3), 215-226.

[12] David, D., Alnoor, H., da Silva Santana, V. M., Bargiela, P., Nur, O., Willander, M., and da Silva, A. F. (2019). Optical properties from photoelectron energy-loss spectroscopy of low-temperature aqueous chemically synthesized $\mathrm{ZnO}$ nanorods grown on Si. Semiconductor Science and Technology, 34(4), 045019. 
[13] Miklos, A., Schäfer, S., Hess, P. (1999). Photoacoustic spectroscopy, Theory. Encyclopedia of Spectroscopy and Spectrometry (Academic, New York), p. 1815.

[14] Low, M. J., Parodi, G. A. (1980). Carbon as Reference for Normalizing Infrared Photoacoustic Spectra, Spectroscopy Letters, 13(9), 663-669. DOI: 10.1080/00387018008076910

[15] Jayalakshmy, M. S., Philip, J. (2010). Thermophysical Properties of Plant Leaves and Their Influence on the Environment Temperature. Int J Thermophys, 31, 2295-2304.

DOI: 10.1007/s10765-010-0877-7

[16] David, D., Godet, C. (2016). Derivation of dielectric function and inelastic mean free path from photoelectron energy-loss spectra of amorphous carbon surfaces. Appl. Surf. Sci., 387, 1125-1139.

[17] Lu, Y., Lu, Y., Hu, H., Xie, F., Wei, X., Fan, X. (2017). Structural characterization of lignin and its degradation products with spectroscopic methods. J. Spectro, 8951658. https://doi.org/10.1155/2017/8951658

[18] Tauc, J., Menth, A. (1972). States in the gap. J Non-Cryst Solids, 569, 8-10.

[19] Mott, N. F., Davis, E. A. (1979). Electron processes in non-crystalline materials. Clarendon, Oxford.

[20] M. Schwanninger, J.C. Rodrigues and K. Fackler, A review of band assignments in near infrared spectra of wood and wood components, J. Near Infrared Spectrosc. 19, 287308 (2011).

[21] Beć, K. B., \& Huck, C. W. (2019). Breakthrough potential in near-infrared spectroscopy: Spectra simulation. A review of recent developments. Frontiers in chemistry, 7, 48.

[22] Hernandez, V. et al. Confinement potential and m-electron delocalization in polyconjugated organic materials. Physical Review B, v. 50, n. 14, p. 9815, 1994.

[23] Lopez, Pedro EM et al. Polarizable empirical force field for aromatic compounds based on the classical drude oscillator. The Journal of Physical Chemistry B, v. 111, n. 11, p. 28732885, 2007.

[24] Lemkul, Justin A. et al. An empirical polarizable force field based on the classical drude oscillator model: development history and recent applications. Chemical reviews, v. 116, n. 9, p. 4983-5013, 2016.

[25] Haensel, T., Reinmöller, M., Lorenz, P., Beenken, W. J., Krischok, S., Ahmed, S. I. U. (2012) Valence band structure of cellulose and lignin studied by XPS and DFT. Cellulose, 19, 1005-1011.

[26] Haensel T., Comouth A., Lorenz P., Ahmed S.I.-U., Krischok S., Zydziak N., Kauffmann A., Schaefer J.A. (2009). Appl. Surf. Sci., 255, 8183-8189. 
DOI: 10.1016/j.apsusc.2009.05.047

[27] Beamson, G., Pickup, B. T., Li, W., Mai, S.-M. (2000). XPS Studies of Chain Conformation in PEG, PTrMO, and PTMG Linear Polyethers. J. Phys. Chem. B, 104, 12, 2656-2672

[28] Lin-Vien, D., Colthup, N. B., Fateley, W. G., Grasselli, J. G. (1991). The Handbook of Infrared and Raman Characteristic Frequencies of Organic Molecules. Academic Press:

Boston.

[29] Bock, P., Gierlinger, N. (2019). Infrared and Raman spectra of lignin substructures: Coniferyl alcohol, abietin, and coniferyl aldehyde. J Raman Spectrosc., 50, 778-792.

DOI: $10.1002 / j r s .5588$

[30] Spectra Lux Software v.2.0, Ponto Quântico Nanodispositivos / RENAMI, 2003, P.A. Santa-Cruz, F.S. Teles.

[31] Tarabanko, V.E.; Tarabanko, N. (2017). Catalytic Oxidation of Lignins into the Aromatic Aldehydes: General Process Trends and Development Prospects. Int. J. Mol. Sci.18, 2421.

[32] Granberg, H., Jensen, J., Mattsson, L. (2003). Forward scattering of fiber-containing surfaces studied by 3-D reflectance distribution simulations and measurements. Opt. Eng. 42, 2384-2390. DOI: 10.1117/1.1589024 